\title{
Induction of C-Mip by IL-17 Plays an Important Role in Adriamycin-Induced Podocyte Damage
}

\author{
Yanbo Liu Lin Su $^{\mathrm{b}}$ Qiuxia Lin ${ }^{\mathrm{a}}$ Ying Han ${ }^{\mathrm{d}}$ Peng You ${ }^{\mathrm{b}}$ Qingfeng Fan ${ }^{\mathrm{d}, \mathrm{e}}$
}

aDepartment of Pediatrics, First Hospital of Jilin University, Changchun, ${ }^{b}$ Department of Gastroenterology, Peking University People's Hospital, Beijing, 'Department of Tissue Engineering, Institute of Basic Medical Sciences and Tissue Engineering Research Center, Academy of Military Medical Sciences, Beijing, 'Department of Pediatrics, Peking University First Hospital, Beijing, PR. China; ePresent address: Renal-Electrolyte and Hypertension Division, Perelman School of Medicine, University of Pennsylvania, Philadelphia, PA 19104, USA

\section{Key Words}

Adriamycin • Podocyte••Treg cell • Th17 cell• IL-17 • c-mip • Nephrin •PPhosphor-nephrin • $\mathrm{NF}-\mathrm{kB} \cdot$ apoptosis

\begin{abstract}
Background/Aims: Although the disturbance of $\mathrm{T}$ lymphocyte and glomerular podocyte exerts a crucial function in the pathogenesis of proteinuria, the potential link is still unclear. Methods: The balance of Treg and Th17 cells, and the expression of IL-17/IL-17R and c-mip were investigated in adrimycin-induced nephropathy (AN) mice. The effect and mechanism of IL-17 on podocyte were explored in cultured podocytes. Results: The proportion of Th17 cells in peripheral blood mononuclear cells, the amount of IL-17 in serum and kidney cortical homogenates, and the expression of IL-17R and c-mip in glomerular podocyte were increased obviously in AN mice. In cultured podocytes, recombinant IL-17 led to an induction of apoptosis and cytoskeletal disorganization, an overproduction of c-mip while downregulation of phosphor-nephrin, and an increased binding of c-mip to NF-KB/RelA. Silence of c-mip prevented podocyte apoptosis and reduction of phosphor-nephrin by prompting nuclear translocation of NF-KB/RelA in IL-17 treated cells. Persistent activation of NF-KB upregulated pro-survival protein $\mathrm{Bcl}-2$ and decreased podocyte apoptosis, but had no effect on phosphor-nephrin level. Conclusion: These findings demonstrated that induction of IL-17 released by Th17 cells plays a key role in podocytopathy most likely through down-regulation of phosphor-nephrin and Bcl-2 level via overproduction of c-mip.
\end{abstract}

Copyright (c) 2015 S. Karger AG, Basel

Y. Liu, L. Su and Q Lin contributed equally to this work.

Peng You, M. D.

and Qingfeng Fan, M. D., Ph. D.

KARGER 125
Department of Gastroenterology, Peking University People's Hospital,

No 11, Xizhimen South Street, Xicheng District, Beijing 100044 (P. R. China) and Renal-Electrolyte and Hypertension Division, Perelman School of Medicine, University of Pennsylvania, CRB 460, 415 Curie Blvd., Philadelphia, PA 19104 (USA)

E-Mail yopeng@163.com and E-Mail qingfeng@mail.med.upenn.edu 


\section{Introduction}

Nephrotic syndrome (NS) is the most common glomerular disease in children and adults, characterized by massive proteinuria, hypo-albuminuria, generalized edema, and hyperlipidemia [1]. In recent decades, it has been well known that podocyte, the glomerular visceral epithelial cell, is required for maintaining the structural integrity of glomerular filtration barrier by extending major processes and foot processes (FPs) from a large cell body and forming the slit diaphragm (SD) between neighboring podocyte FPs, which establishes the permselectivity of glomerular filter $[1,2]$. Upon podocyte injury, the alteration of FPs and SD results in effacement of FPs and leads to the development of proteinuria [1,2]. Although proteinuria is the major and independent risk factor for the progression of kidney diseases to end stage renal failure, the underlying mechanism remains unclear.

Nephrin, a key component of SD, not only serves as a structural linker between the SD and the actin cytoskeleton, but also participates in the signaling events that regulate the overall structure and function of podocyte since the intracellular domain of nephrin has 10 tyrosine residues that are phosphorylated by the Src kinase Fyn [3]. Several clinical and experimental observations showed reduction of tyrosine phosphorylated nephrin (phosphor-nephrin) in some proteinuric glomerular diseases $[4,5]$. It was reported that c-maf inducing protein (c-mip) is overproduced in podocytes during glomerular damage and interferes with podocyte signaling by preventing the interaction of nephrin with Fyn, thereby decreasing nephrin phosphorylation [6]. Moreover, c-mip inhibits the interaction between nephrin and the adaptor protein Nck and between Fyn and the actin nucleation protein N-WASP, potentially accounting for cytoskeletal disorganization and FPs effacement [6]. It should be noted that c-mip was firstly identified in T lymphocytes of patients with minimal change nephritic syndrome (MCNS) experiencing a relapse [7]. Higher expression of B7-1 (also termed CD80), a co-stimulatory molecule generally present on the surface of B lymphocytes and antigen-presenting cells, was also found in glomerular podocytes in human and experimental NS [8]. The induction of c-mip and B7-1 in both lymphocytes and podocytes provides further evidence that there may be some relationship between lymphocyte and podocyte in MCNS. Early in 1970s, it was proposed that MCNS is a disorder of lymphocyte function with increased levels of lymphocyte-released cytokines, which could induce podocyte injury and thus increase glomerular permeability to plasma proteins [9]. Although the findings of disturbance of both lymphocyte and glomerular podocyte in the disease suggest that a putative factor produced by immune cells may alter podocyte function leading to nephrotic proteinuria, the mechanism underlying the pathophysiology of podocyte damage and proteinuria development is still not understood very well.

Recently, regulatory T cells (Treg cells) and T-helper17 (Th17) cells have been described as two distinct subsets that play opposite roles [10]. It was reported that the severity of NS is associated with the decreased activity of Treg cells $[9,11,12]$. Similar finding showed that peripheral blood mononuclear cells (PBMC) of children with NS exhibited a reduction in Treg cells that is in parallel to an increase in Th17 cells [13]. Treg cells have an anti-inflammatory role and maintain tolerance to self-components through direct contact with cells or by releasing anti-inflammatory cytokines such as IL-10 and TGF- $\beta[9,14]$. Nevertheless, Th17 cells play a key role in induction of autoimmune tissue injuries and inflammation by releasing IL-17 [15]. Therefore, the disturbance of Treg and Th17 cells may alter the balance of cytokines production thus possibly leading to podocyte injury in NS diseases.

In the current study, the proportion of Treg and Th17 cells in PBMC as well as the serum level of some related cytokines have been evaluated in adriamycin (ADR)-induced nephropathy (AN) mice, in which podocyte is regarded as a predominant target of injury [16, 17]. The effects of recombinant IL-17 (rIL-17) on c-mip expression and phosphor-nephrin level were investigated in cultured mouse podocyte. 


\section{Cellular Physiology Cell Physiol Biochem 2015;36:1274-1290 \begin{tabular}{l|l} 
and Biochemistry Published online: July UI, 2015 & $\begin{array}{l}\text { ( ) 2015 S. Karger AG, Basel } \\
\text { www.karger.com/cpb }\end{array}$ \\
\hline
\end{tabular}}

Liu et al.: Role of IL-17-Induced C-Mip in Podocyte Injury

\section{Materials and Methods}

Mouse adriamycin nephropathy model

Male BALB/c mice weighing 20 to $25 \mathrm{~g}$ were used in this study. All animal procedures were approved by the Animal Ethics Committee of Jilin University First Hospital (Jilin, China). An optimized dose $10.5 \mathrm{mg} /$ kg body weight of doxorubicin hydrochloride (Adriamycin: ADR, Sigma) or the equal volume of saline as control was injected once via the tail vein of each mouse. Eight mice each group were killed at day 5, 7, 14 and 21 after ADR injections. Blood, urine, and kidney were harvested for further analysis. Mice were perfused with cold PBS (50 ml) before kidney was removed. All urine and blood specimens were analyzed by using a BM/Hitachi 747 analyzer (Tokyo, Japan) for 24-h albuminuria (mg) as well as serum albumin $(\mathrm{g} / \mathrm{L})$ and creatinine $(\mu \mathrm{mol} / \mathrm{L})$, respectively.

\section{Mouse podocyte culture and treatment}

Immobilized mouse podocyte clone from Dr. P. Mundel was cultured at $33^{\circ} \mathrm{C}$ for proliferation in RPMI 1640 media supplemented with 10\% fetal calf serum (Gibco), $100 \mathrm{U} / \mathrm{ml}$ Penicillin/Streptomycin, and $15 \mathrm{U} /$ $\mathrm{ml}$ murine recombinant $\gamma$-interferon (Life Technologies). After 1 week, cells were transferred to collagen I coated plates and differentiated at $37^{\circ} \mathrm{C}$ for 14 days by removal of $\gamma$-interferon. Differentiated podocytes were treated with $100 \mathrm{ng} / \mathrm{ml}$ of recombinant mouse IL-17 (R\&D) for different time points. Cells between passages 15 and 25 were used in this study. Apoptotic podocytes was assessed by using flow cytometry assay through AnnexinV-FITC and PI staining (BD Biosciences). Lentiviral shRNA was used to silence the expression of mouse c-mip. The validated shRNA sequence of mouse c-mip is 5'- ctcttcacccaggagtatatctc-3'. Non-target shRNA lentiviral particles were used as control. Podocytes were cultured in 60 -mm plates, and $10 \mu \mathrm{l}$ of shRNA lentivirus $\left(10^{6} \mathrm{TU}\right)$ were applied for $48 \mathrm{~h}$. In this study, phorbol 12-myristate 13-acetate (PMA: $100 \mathrm{nM}$ ) was used to induce persistent activation of NF- $\mathrm{\kappa B}$.

\section{ELISA assay}

The levels of mouse serum TGF- $\beta$, IL-17, IL-23, IL-10, IL-6, and IL-4 were measured using EnzymeLinked Immunosorbent Assay (ELISA) according to the instructions of manufacturers (Abcam). All samples were used in duplicate.

\section{Analysis of Th17 and Treg cells}

Peripheral blood mononuclear cells (PBMCs) were obtained by standard procedure. For analysis of Th17, $1 \times 10^{6}$ cells per ml were cultured in a 24-well plate in RPMI 1640 media containing $100 \mathrm{U} / \mathrm{ml}$ Penicillin/Streptomycin, $2 \mathrm{mM}$ glutamine, and 10\% fetal calf serum. Cultures were stimulated with PMA (50 $\mathrm{ng} / \mathrm{ml})$, ionomycin ( $2 \mu \mathrm{M}$; BD Biosciences) and monensin $(1 \mu \mathrm{g} / \mathrm{ml}$; Sigma $)$ at $37^{\circ} \mathrm{C}$ for $5 \mathrm{~h}$. Cells were washed twice with $1 \mathrm{x}$ phosphate-buffered saline (PBS), and incubated with APC conjugated anti-CD4 antibody (BD Biosciences) at $4{ }^{\circ} \mathrm{C}$ for $20 \mathrm{~min}$. For analysis of Treg, PBMCs were incubated with FITC conjugated anti-CD4 and PE conjugated anti-CD25 antibodies at $4{ }^{\circ} \mathrm{C}$ for $30 \mathrm{~min}$. Following surface labeling, cells were washed twice, fixed and permeabilized, and then stained with PE conjugated anti-IL-17A antibody (eBioscience) for Th17 detection or with APC conjugated anti- Foxp3 antibody (eBioscience) for Treg detection. Normal isotype controls were given to enable correct compensation and confirm antibody specificity. Stained cells were analyzed by using flow cytometric analysis (FACscan).

\section{Quantitative RT-PCR}

Total RNA was extracted from cultured podocytes, mouse PBMCs and kidney cortex with TRIzol reagent (Life Technologies), and $2 \mu \mathrm{g}$ of RNA was reversely transcribed to cDNA using cDNA synthesis kit (Life Technologies). Equal amount of cDNA $(2 \mu \mathrm{l})$ was used to perform quantitative PCR with SYBR Green Mix (Bio-Rad) on 7700 real-time PCR Detection System (Applied Biosystems) for expressions of c-mip, ROR $\gamma$ t, Foxp3, and IL-17R. The primer sequences are listed (Table 1). Expression level was normalized to GAPDH. Data are shown as fold change to control.

\section{Immunoblotting and Immunoprecipitation assay}

Total protein was extracted from cultured podocytes and renal cortex or isolated glomeruli using sequential sieving with modified RIPA buffer (150 mM NaCl, 1\% NP-40, 0.1\% SDS, 0.5\% DOC, $50 \mathrm{mM}$ Tris/HCl 


\section{Cellular Physiology Cell Physiol Biochem 2015;36:1274-1290 \begin{tabular}{ll|l} 
and Biochemistry & $\begin{array}{l}\text { DOI: 10.1159/000430296 } \\
\text { Published onInne: July U1, } 2015\end{array}$ & $\begin{array}{l}\text { ( 2015 S. Karger AG, Basel } \\
\text { www.karger.com/cpb }\end{array}$ \\
\hline
\end{tabular}}

Liu et al.: Role of IL-17-Induced C-Mip in Podocyte Injury

Table 1. Primer sequences for real-time PCR

\begin{tabular}{lll}
\hline Gene & \multicolumn{1}{c}{ Forward Primer } & \multicolumn{1}{c}{ Reverse Primer } \\
\hline RORYt & 5'-ttttccgaggatgagattgc-3' & 5'-ctttccacatgctggctaca-3' \\
Foxp3 & 5'-cagctctgctggcgaaagtg-3' & 5'-tcgtctgaaggcagagtcagga-3' \\
c-mip & 5'-gctgcttgggagcgacgtgt-3' & 5'-cgttaggtggtgcggctccc-3' \\
IL-17R & 5'-ctgatggggacccaaaccac-3' & 5'-ccacagggtgaagctcacac-3' \\
GAPDH & 5'-tgtgtccgtcgtggatctga-3' & 5'-cctgcttcaccaccttcttga-3' \\
\hline
\end{tabular}

pH7.4, 20\% glycerol) supplemented with protease and phosphotase cocktail inhibitors (Roche). Cytosolic and nuclear fractions were also extracted by using Qproteome Cell Compartment Kit (Qiagen). Totally, 100 $\mu \mathrm{g}$ of protein was used to run $7.5 \%$ or $15 \%$ SDS-PAGE, and then transferred to nitrocellulose membrane (Thermo Scientific). Membranes were rinsed once with Tris-buffered saline containing 0.05\% Tween-20 (TTBS), and thereafter blocked for $45 \mathrm{~min}$ in 5\% BSA/TTBS to decrease non-specific background from the binding of primary antibodies. The membranes were then incubated with the indicated primary antibodies at $4{ }^{\circ} \mathrm{C}$ for overnight. After 5 times washes with TTBS, membranes were incubated with HRP-conjugated secondary antibody for $1 \mathrm{~h}$ at room temperature. Blots were developed with an ECL chemiluminescence detection kit (Pierce). The specific band was scanned and then quantified with Image J 1.49 (http://imagej. nih.gov/ij).

Interaction of c-mip and NF- $\kappa B /$ RelA (p65) was measured by using immunoprecipitation assay. Totally, $300 \mu \mathrm{g}$ of lysis was incubated for $2 \mathrm{~h}$ at $4{ }^{\circ} \mathrm{C}$ with $2 \mu \mathrm{g}$ of mouse anti-NF- $\mathrm{kB} /$ RelA (p65) antibody (Sigma), followed by incubation with $25 \mu \mathrm{l}$ Protein G Sepharose (GE Healthcare Bioscience) at $4{ }^{\circ} \mathrm{C}$ for overnight. The beads were washed five times with $0.05 \%$ NP-40/PBS, and the precipitated proteins were resolved by $10 \%$ SDS-PAGE and analyzed by immunoblotting with rabbit anti-c-mip antibody (Proteintech). Notably, normal non-immune mouse IgG (Alpha Diagnostics, San Antonio) was used as negative control.

\section{Immunofluorescence staining}

Differentiated podocytes were treated with $100 \mathrm{ng} / \mathrm{ml}$ of recombinant human IL-17 (R\&D) for 6, 12, 24 and 48 h, respectively. Cells were fixed with 4\% paraformaldehyde (PFA) freshly prepared in PBS, and permeabilized with $0.25 \%$ TritonX-100/PBS. For labeling of actin cytoskeleton, Alexa 594-conjugated phalloidin (Invitrogen) was used. For staining of IL-17R, mouse anti-IL-17R (Abcam) was incubated for overnight at $4{ }^{\circ} \mathrm{C}$. Double staining of c-mip and NF- $\mathrm{KB} /$ RelA (p65) was performed by incubation with rabbit anti-c-mip and mouse anti-NF-кB/RelA (p65) antibodies. After 3 washes, Alexa 594 or 488 -conjugated goat anti-mouse IgG and Alexa 594 conjugated goat anti-rabbit IgG (Invitrogen) were applied for $1 \mathrm{~h}$. Then, coverslips were mounted with ProLong gold antifade reagent (Invitrogen).

Tissue staining of c-mip and IL-17R was performed on frozen kidney sections from AN mice. Tissue sections were fixed with 4\% PFA/PBS, and permeabilized with $0.25 \%$ TritonX-100/PBS. To remove or decrease non-specific binding, sections were incubated with $10 \%$ goat serum/PBS. Then, rabbit anti-c-mip and mouse anti-synaptopodin (Progen) antibodies, or mouse anti-IL-17R and rabbit anti-podocin antibodies (Abcam) were applied for $2 \mathrm{~h}$ at room temperature. After 3 washes with PBS, Alexa 594-conjugated goat anti-rabbit IgG and Alexa 488-conjugated goat anti-mouse IgG (Invitrogen) were added and incubated for 1 h. After 3 washes, sections were mounted with ProLong gold antifade reagent. Images were taken by using laser scanning confocal microscope (LSM550, Zeiss) and processed with Photoshop CS6 (Adobe Systems).

\section{Statistical Analysis}

Statistical evaluation was performed by using One-way ANOVA followed by Tukey's multiple comparison test (Prism 4.0, GraphPad). Results are presented as the mean \pm SEM. A $p<0.05$ was regarded as significant statistical differences. 


\section{Cellular Physiology Cell Physiol Biochem 2015;36:1274-1290 \begin{tabular}{l|l} 
DOI: 10.1159/000430296 & O 2015 S. Karger AG, Basel
\end{tabular} and Biochemistry Publisned onlne: July ul, 2015 www.karger.com/cpb}

Liu et al.: Role of IL-17-Induced C-Mip in Podocyte Injury

\section{Results}

Induction of c-mip in ADR-induced nephropathy (AN) mice

As previously reported $[16,18]$, mice nephropathy induced by injection of adriamycin $(10.5 \mathrm{mg} / \mathrm{ml})$ in the present study, was evidenced by the evaluation of 24-h albuminuria, serum albumin and creatinine. In comparison with day $0(0.67 \pm 0.13 \mathrm{mg})$, proteinuria developed obviously $(p<0.05)$ at day $5(6.50 \pm 0.50 \mathrm{mg})$, peaked at day $7(21.75 \pm 1.60$ $\mathrm{mg})$ and continued to day $14(17.38 \pm 0.92 \mathrm{mg})$ and day $21(15.23 \pm 0.73 \mathrm{mg})$ in mice with ADR injections (Fig. 1A). Correspondingly, the concentration of serum albumin decreased significantly $(p<0.05)$ at day $7(17.38 \pm 1.13 \mathrm{~g} / \mathrm{L})$, day $14(15.43 \pm 1.17 \mathrm{~g} / \mathrm{L})$ and day $21(17.08$ $\pm 1.25 \mathrm{~g} / \mathrm{L})$ in AN mice compared to day $0(24.69 \pm 1.76 \mathrm{~g} / \mathrm{L})$ (Fig. 1B). Nevertheless, the increase of serum creatinine was detected $(p<0.01)$ at day $21(26.09 \pm 2.22 \mu \mathrm{mol} / \mathrm{L})$ as compared with day $0(10.73 \pm 1.42 \mu \mathrm{mol} / \mathrm{L})$ (Fig. 1C).

Induction of c-mip was initially identified in lymphocytes of patients with minimal change nephrotic syndrome [7]. Up-regulation of c-mip has been reported in several glomerular diseases and some experimental kidney diseases $[6,19,20]$. In this study, we investigated the expression change of c-mip in peripheral blood mononuclear cells (PBMC) and kidney tissues from AN mice. At mRNA level, quantitative PCR data showed that compared to day 0 $(1.00 \pm 0.00)$, expression of c-mip increased significantly $(p<0.05)$ since day $7(2.53 \pm 0.20)$ and continued to day $14(3.26 \pm 0.30)$ and day 21 (3.16 \pm 0.26$)$ in kidney tissues (cortex) following ADR injections. Nevertheless, in PBMCs, ADR induced a rapid increase of c-mip

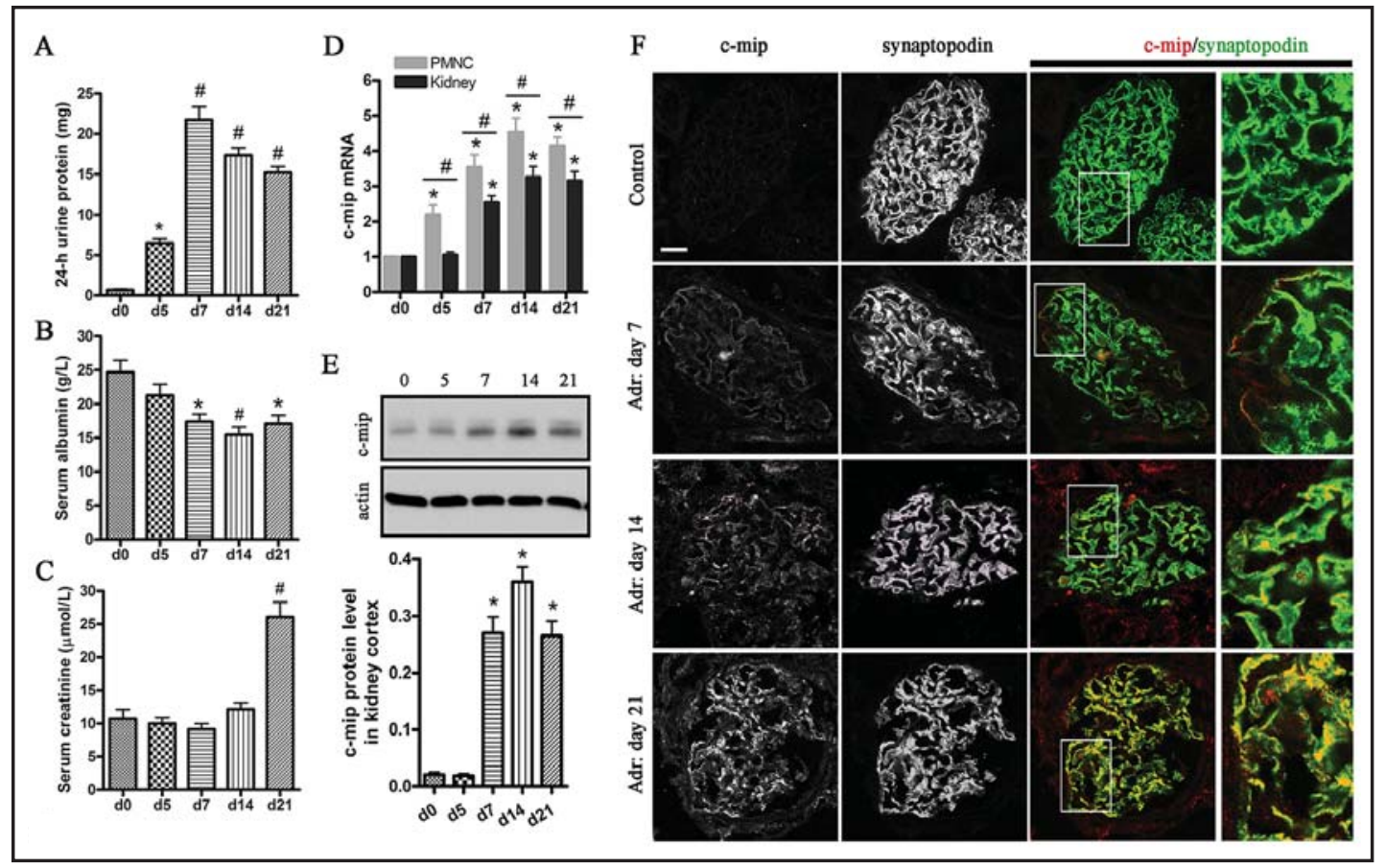

Fig. 1. Induction of c-mip in ADR-induced nephropathy (AN) mice. AN was induced by tail vein injection of adriamycin in mice, and characterized by 24-h proteinuria (A), hypoalbuminemia (B), and hypercreatininemia (C). Data are shown as mean \pm SEM. $n=8$. ${ }^{*} p<0.05$ vs. day $0,{ }^{*} p<0.001$ vs. day 0 . (D) Effects of ADR on expression of c-mip were measured at mRNA level by using real time RT-PCR in peripheral blood mononuclear cells (PBMCs) and kidney cortex. Data are shown as mean \pm SEM. $n=6$. ${ }^{*} \mathrm{p}<0.05$ vs. day 0 , ${ }^{\#} \mathrm{p}<0.01$ vs. PBMCs. (E) Immunoblotting assay was used for expression of c-mip at protein level in kidney cortex from AN mice. Data are shown as mean \pm SEM. $n=8$. ${ }^{*} p<0.001$ vs. day 0. (F) Expression and distribution change of c-mip (red) and podocyte marker synaptopodin (green) was revealed in AN mice kidney by using indirect immunofluorescence staining. Representative images are shown, and the enlarged pictures are displayed at far right. Bar $=25 \mu \mathrm{m}$. 


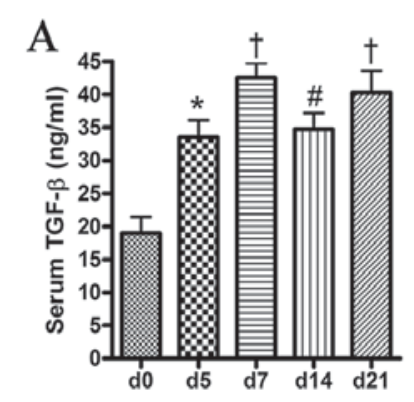

$\mathrm{D}$

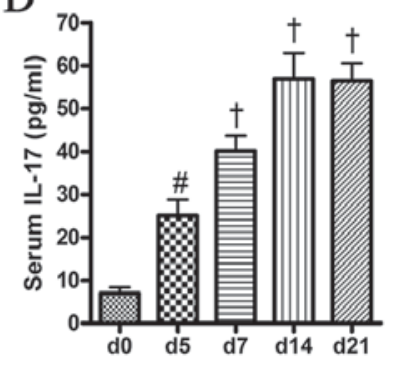

B

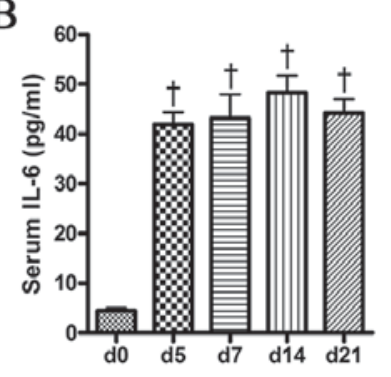

$\mathrm{E}$

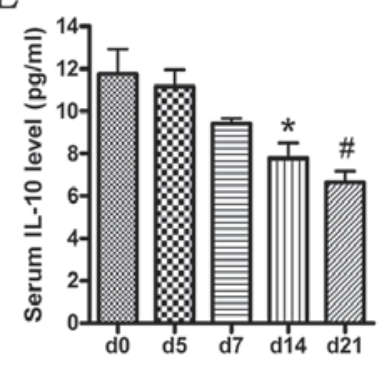

C

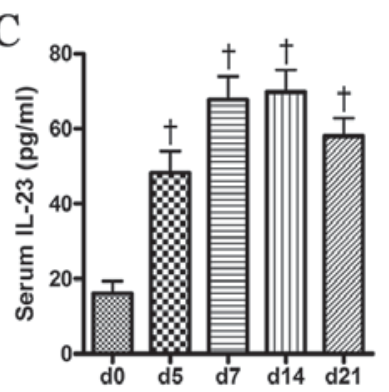

$\mathrm{F}$

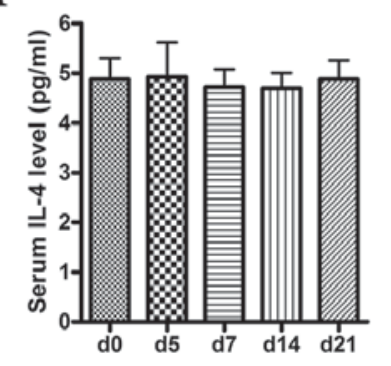

Fig. 2. Changes of serum cytokines in ADR-induced nephropathy (AN) mice. AN was induced by tail vein injection of adriamycin in mice, and the level of serum cytokines was evaluated by ELISA. The level of serum TGF- $\beta$ (A), IL-6 (B), IL-23 (C), and IL-17 (D) were increased, whereas IL-10 (E) was decreased in AN mice. ADR showed no impacts on serum IL-4 level (F). Data are shown as mean \pm SEM. $n=3$. ${ }^{*} p<0.05$ vs. day 0 , " $p$ $<0.01$ vs. day $0,{ }^{\dagger} \mathrm{p}<0.001$ vs. day 0 .

mRNA level at day $5(2.20 \pm 0.27)$, which continued to day 7 (3.54 \pm 0.35$)$, day 14 (4.53 \pm 0.40 ) and day $21(4.15 \pm 0.24)$ (Fig. 1D). Notably, the mRNA level of c-mip in PBMCs was much higher $(p<0.01)$ at day 5, 7, 14 and 21 than in kidney (Fig. 1D). In kidney tissues, the abundance of c-mip was further explored at protein level by using Immunoblotting assay. Relative to $\beta$-actin, the amount of c-mip protein was very low in control mice kidney $[0.02$ $\pm 0.004)$. ADR injections led to an abrupt up-regulation $(p<0.001)$ of c-mip at day $7(0.27 \pm$ $0.029)$ persisting to day $14(0.36 \pm 0.026)$ and day 21 (0.27 \pm 0.026$)$ (Fig. 1E).

To further clarify the distribution change of c-mip in glomeruli, double immunofluorescence labeling of c-mip and synaptopodin was performed in frozen kidney sections. Synaptopodin, a differentiated podocyte marker, is an actin-associated protein that may play a crucial role in actin-based cell shape and motility. A linear distribution pattern of synaptopodin was revealed along glomerular capillary loops, and c-mip staining was not observed in normal mice glomeruli. Intensity of c-mip increased obviously, whereas synaptopodin decreased at day 7,14 and 21 in AN mice glomeruli. Moreover, distribution change of synaptopodin occurred remarkably in AN mice, displaying as a punctate or dotlinear like manner. Co-localization of c-mip and synaptopodin was observed clearly in AN mice glomeruli, indicating an induction of c-mip by ADR in glomerular podocyte (Fig. 1F).

\section{Serum cytokines change in ADR-induced nephropathy (AN) mice}

The mechanism by which ADR induces podocyte injury has been widely investigated, including both non-immune and immune factors $[16,21]$. The level of several serum cytokines was assessed in the mice AN model, including TGF- $\beta$, IL-6, IL-23, IL-17, IL-10 and IL-4. In comparison with day 0 , the serum levels of TGF- $\beta$, IL-6, IL-23, and IL-17 increased significantly $(p<0.05)$ since day 5 and persisted to day 21 in AN mice (Fig. 2). Nevertheless, serum IL-10 level decreased obviously $(p<0.05)$ at day 14 and day 21 in AN mice (Fig. 2). Compared to control, there was no obvious change of serum IL-4 level at any observed time points in AN mice (Fig. 2). 


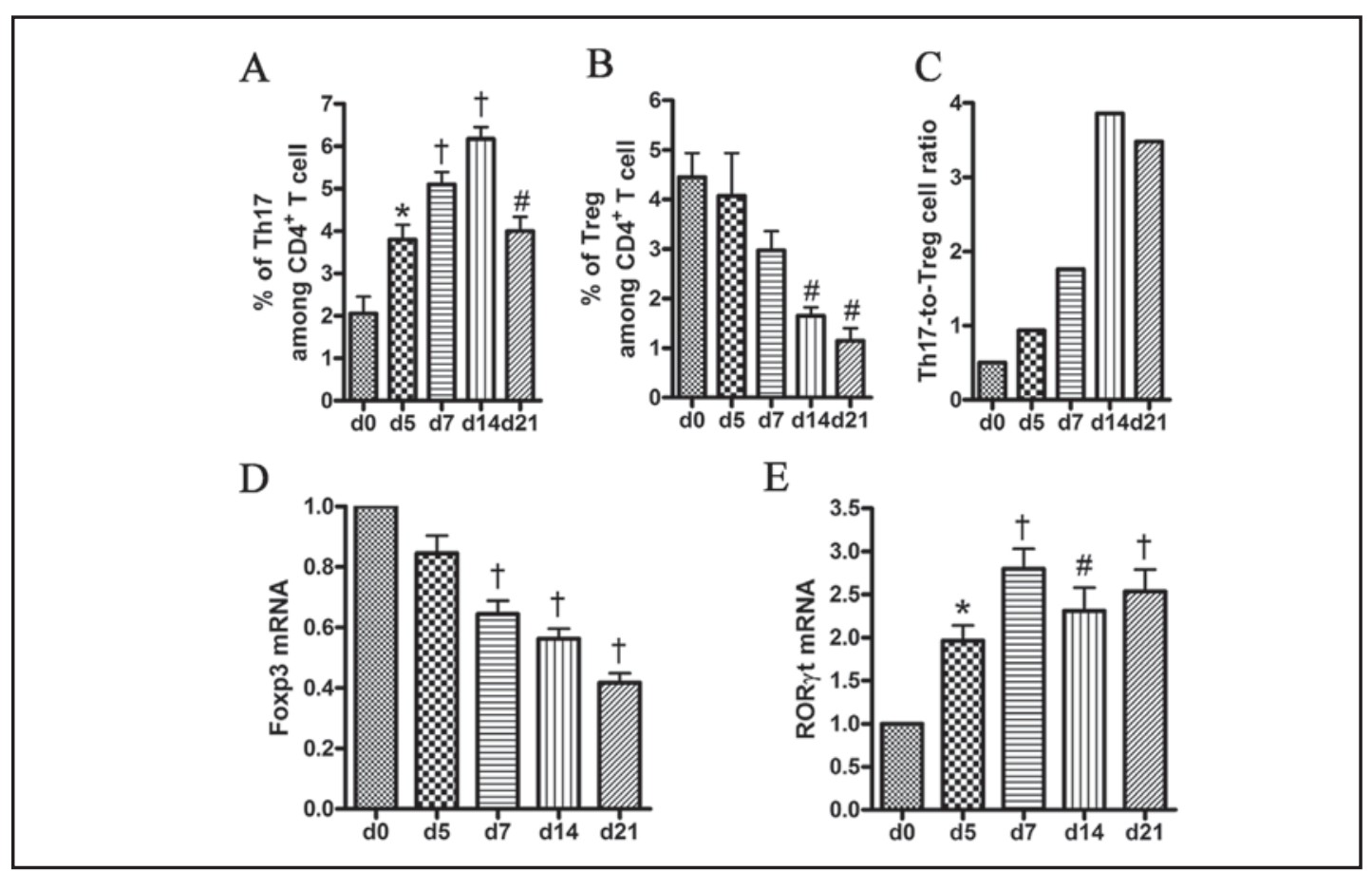

Fig. 3. Imbalance of circulating Th17 and Treg cells in ADR-induced nephropathy (AN) mice. Peripheral blood mononuclear cells (PBMCs) were isolated from AN mice. For analysis of Th17, cultured PBMCs were stimulated with phorbol myristate acetate (PMA), ionomycin and monensin, and then labeled with anti-CD4 and anti-IL-17 antibodies. For analysis of Treg, PBMCs were labeled with anti-CD4 and anti-CD25 as well as anti-Foxp3 antibodies. Flow cytometry was used to determine the amount of Th17 and Treg cells. The percentage of Th17 among total CD4+ cells was increased significantly (A), while Treg was decreased remarkably (B) in ADR nephropathy mice. ADR injection increased the ratio of Th17 to Treg cells (C). Total RNA was extracted from PBMCs and quantitative PCR was performed for mRNA expressions of transcript factors Foxp3 and ROR $\gamma \mathrm{t}$, respectively. The mRNA level of Foxp3 (D) was decreased obviously, whereas ROR $\gamma \mathrm{t}$ (E) was increased significantly in AN mice. Data are shown as mean \pm SEM. $\mathrm{n}=3$. ${ }^{*} \mathrm{p}<0.05$ vs. day 0 , ${ }^{\#} \mathrm{p}<0.01 v s$. day $0,{ }^{\dagger} \mathrm{p}<0.001$ vs. day 0 .

\section{Imbalance of circulating Th17 and Treg cells in ADR-induced nephropathy (AN) mice}

Regulatory T cells (Treg cells) and T helper 17 (Th17) cells have been described as two distinct subsets from Th1 and Th2 cells that play opposite roles in some inflammatory and/ or immune diseases [10]. Th17 cells are a subset of T helper cells producing interleukin 17 (IL-17) and IL-23. TGF- $\beta$ and IL- 6 is thought to drive differentiation of Th17 cells in mouse. On the other hand, IL-10 is required for the production of Treg cells. The profiling of serum cytokines that our data revealed suggested that the population of Th17 cells increased while Treg cells decreased in AN mice (Fig. 2). Here, the percentage of Th17 and Treg cells among $\mathrm{CD} 4^{+} \mathrm{T}$ cells has been analyzed with flow cytometry assay.

In comparison with day 0 , the percentage of Th17 cells increased obviously $(p<0.05)$ since day 5 and peaked at day 14 , whereas Treg cells decreased dramatically $(p<0.01)$ at day 14 and day 21 in AN mice (Fig. 3A, B). In normal mice, Treg cells are a predominant subset of CD4+ T cells, whereas the ratio of Th17 to Treg cells was robustly reversed since day 7 following ADR injections (Fig. 3C), implying that the balance between Th17 and Treg cells was completely disrupted in AN mice.

To confirm the population changes of Th17 and Treg cells, the level of transcription factors ROR $\gamma \mathrm{t}$ and Foxp3 that are respectively responsible for differentiation of Th17 and Treg cells [10], was assessed by using quantitative PCR assay. Our results showed that the mRNA level of Foxp3 normalized to control (day 0) decreased significantly $(p<0.001)$ at day $7(0.65 \pm 0.044)$, day $14(0.56 \pm 0.034)$ and day $21(0.42 \pm 0.031)$, whereas RORyt mRNA 


\section{Cellular Physiology Cell Physiol Biochem 2015;36:1274-1290 \begin{tabular}{|l|l|}
\hline DOI: 10.1159/000430296 & (C) 2015 S. Karger AG, Basel
\end{tabular} \begin{tabular}{l|l} 
and Biochemistry Published onIne: July U1, 2015 & www.karger.com/cpb
\end{tabular}}

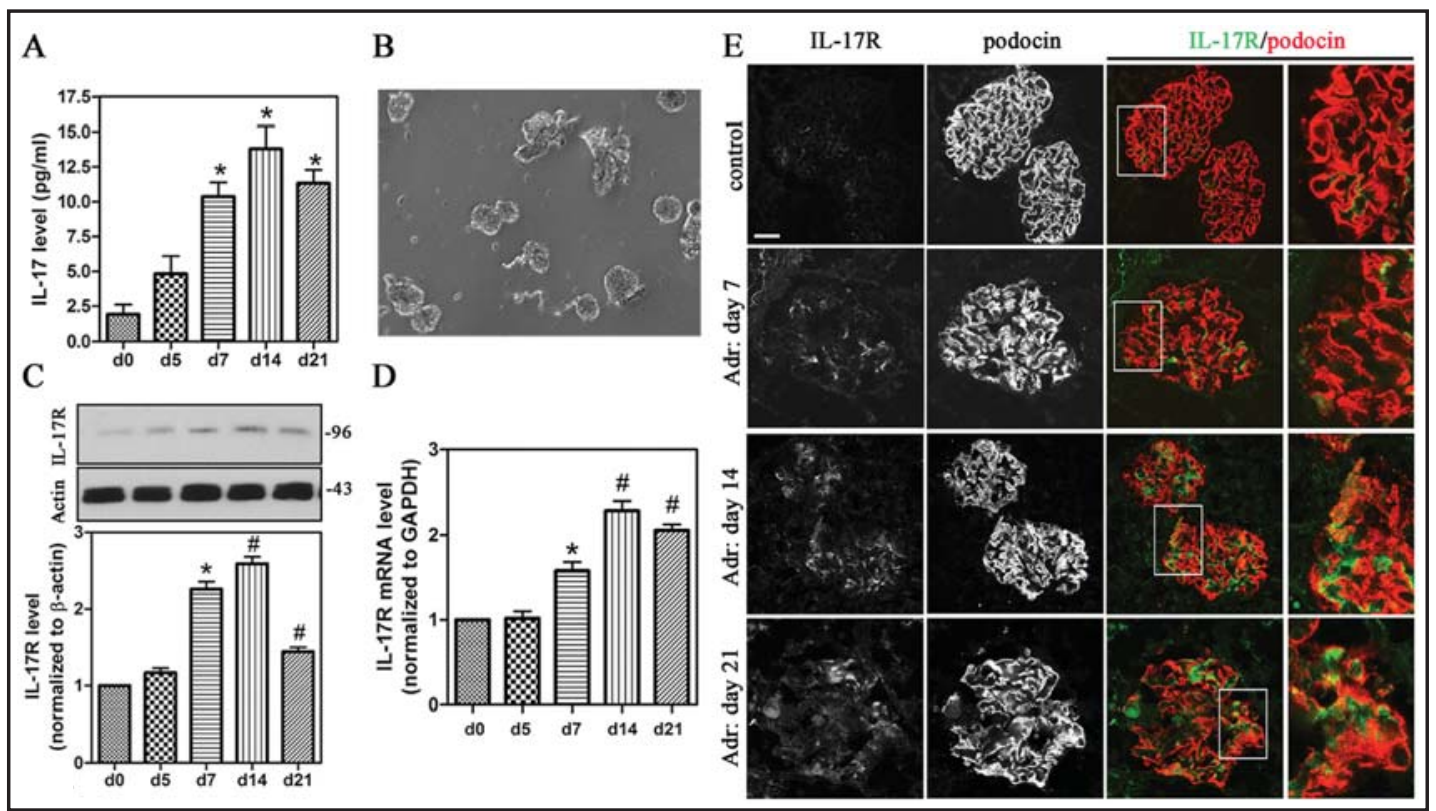

Fig. 4. Induction of IL-17R in ADR-induced nephropathy (AN) mice. AN was induced by tail vein injection of adriamycin in mice. (A) Homogenate of kidney cortex was prepared, and the level of IL-17 was measured by using ELISA. Data are shown as mean \pm SEM. $n=3$. ${ }^{*} p<0.001 v$ s. day 0 . (B) Mouse glomeruli were isolated by using sequential sieving procedure and the purity $(\sim 60 \%)$ of glomeruli was confirmed under microscope. (C, D) Total protein and RNA was extracted from the isolated glomeruli. The mRNA and protein levels of IL17R were analyzed by using Western blot (C) and real time PCR (D), respectively. Data are shown as mean \pm SEM. $\mathrm{n}=3$. ${ }^{*} \mathrm{p}<0.05$ vs. day 0 , ${ }^{*} \mathrm{p}<0.01$ vs. day 0. (E) Expression and distribution of IL-17R (green) and a podocyte marker podocin (red) was revealed in AN mice kidney by immunofluorescence staining. Representative images are shown, and the enlarged pictures are displayed at far right. Bar $=25 \mu \mathrm{m}$.

increased obviously $(p<0.05)$ since day $5(1.97 \pm 0.177)$ and persisted to day 21 (day 7: 2.80 \pm 0.229 ; day 14: $2.31 \pm 0.266$; day 21: $2.54 \pm 0.251$ ) in AN mice (Fig. 3D, E).

\section{Induction of IL-17R in ADR-damaged podocyte}

Interleukin-17 receptor (IL-17R), a cytokine receptor which binds IL-17A, has a large cytoplasmic tail providing docking sites for numerous signaling intermediates [22]. Induction of serum IL-17 by ADR prompted us to address whether IL-17 is involved in glomerular podocyte damage in AN mice. The amount of IL-17 was firstly measured in homogenate of kidney cortex from AN mice. As compared with day 0 (1.90 \pm 0.71$)$, the level of IL-17 in kidney cortex increased significantly $(p<0.001)$ at day $7(10.36 \pm 1.02)$, persisting to day 14 $(13.79 \pm 1.62)$ and day 21 (11.32 \pm 0.97$)$ following ADR injections (Fig. 4A).

Mouse glomeruli were then isolated by using regular sequential sieving method, and the purity $(\sim 65 \%)$ of glomeruli was checked under microscope (Fig. 4B). The amount of glomerular IL-17R was evaluated both at protein and mRNA level in AN mice. Immunoblotting assay revealed that in comparison with day $0(1.0 \pm 0.00)$, the protein level of IL-17R increased significantly $(p<0.05)$ at day $7(2.26 \pm 0.098)$ and continued to day $14(2.59 \pm$ $0.089)$ and day 21 (1.45 \pm 0.053$)$ after ADR injections (Fig. 4C). Similarly, IL-17R mRNA level measured by quantitative PCR in AN mice glomeruli increased remarkably $(p<0.05)$ at day $7(1.58 \pm 0.104)$ continuing to day $14(2.28 \pm 0.116)$ and day $21(2.06 \pm 0.068)$ compared to day $0(1.0 \pm 0.00)$ (Fig. 4D).

Localization and distribution change of IL-17R was further analyzed by immunofluorescence staining in AN mice glomeruli. Podocin, a specific marker of podocyte, was used to indicate the position of podocyte. In normal mice kidney, IL-17R expression was not observed, while podocin showed very strong staining and a well linear distribution pattern along 


\section{Cellular Physiology Cell Physiol Biochem 2015;36:1274-1290 \begin{tabular}{l|l|l}
\hline DOI: 10.1159/000430296 & O 2015 S. Karger AG, Basel
\end{tabular} and Biochemistry Publisned online: July U1, 2015 www.karger.com/cpb}

Fig. 5. Induction of IL-17R by ADR in cultured mouse podocytes. Podocytes were treated with $0.5 \mu \mathrm{g} / \mathrm{ml}$ of adriamycin (ADR) for different time points. (A) Total protein was extracted and immunoblotting assay was used for the expression of IL-17R. Data are shown as mean \pm SEM. $n=3$ independent experiments. ${ }^{*} \mathrm{p}<0.001$ vs. 0 h. (B) Expression and distribution change of IL17R (red color) was displayed by immunofluorescence staining. Absence of anti-IL-

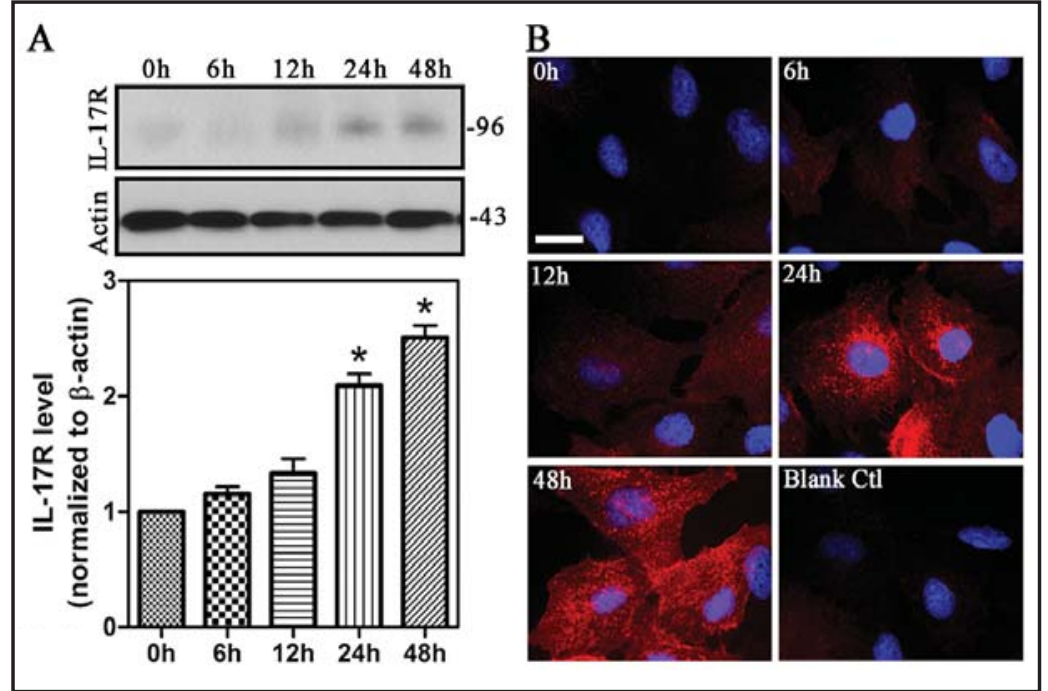
17R antibody was used as blank control (Ctl) to show the specific and positive staining of IL-17R. Bar $=25$ $\mu \mathrm{m}$.

glomerular capillary loops. ADR injection induced an obvious increase of IL-17R in glomeruli since day 7 persisting to day 14 and 21 . Obvious change of podocin intensity was not observed in AN mice glomeruli. Nevertheless, ADR resulted in a significant distribution change of podocin presenting as a punctate or dot-linear manner. At day 7, most of IL-17R seemed to be localized in mesangial or endothelial cells, while colocalization of IL-17R and podocin was clearly revealed at day 14 and day 21 in AN mice glomeruli (Fig. 4E), suggesting that up-regulation of IL-17R in podocyte may play an important role in mice AN.

Induction of IL-17R by ADR in glomerular podocyte was further confirmed in vitro. ADR was applied to the cultured mouse podocyte for different time periods. Immunoblotting assay detected a specific band of IL-17R with the expected size of $96 \mathrm{kDa}$ (Fig. 5A). As compared with control ( $0 \mathrm{h:} 1.0 \pm 0.00)$, quantitative data displayed a remarkable $(p<0.001)$ induction of IL-17R at $24 \mathrm{~h}(2.09 \pm 0.105)$ and $48 \mathrm{~h}(2.51 \pm 0.109)$ after ADR treatment (Fig. 5A). Immunofluorescence staining revealed that intensity of IL-17R increased obviously since 6 $\mathrm{h}$ after ADR application. Notably, robust increase of IL-17R was observed at $24 \mathrm{~h}$ and $48 \mathrm{~h}$ in ADR-treated podocytes (Fig. 5B).

\section{Podocyte damage induced by recombinant mouse IL-17 (rIL-17)}

The role of IL-17 was addressed in cultured podocytes. Firstly, effects of recombinant mouse IL-17 (rIL-17, $100 \mathrm{ng} / \mathrm{ml}$ ) on podocyte apoptosis was investigated in cultured mouse podocyte. As compared with control $(0 \mathrm{~h}: 3.70 \pm 0.654)$, the percentage of apoptotic cells increased significantly $(p<0.001)$ at $24 \mathrm{~h}(9.35 \pm 0.335)$ and $48 \mathrm{~h}(12.58 \pm 0.779)$ in rIL-17 treated podocytes (Fig. 6A).

Immunoblotting assay also showed that compared to $0 \mathrm{~h}(1.0 \pm 0.00)$, application of rIL17 induced a significant $(p<0.01)$ increase of the cleaved/activated caspase 3 at $12 \mathrm{~h}(1.67$ $\pm 0.147), 24 \mathrm{~h}(2.08 \pm 0.112)$ and $48 \mathrm{~h}(1.96 \pm 0.098)$ (Fig. 6B). Moreover, the level of proapoptotic protein Bax and cytochrome c (Cyt c) was also increased remarkably $(p<0.01)$ at 12 h (Bax: $1.98 \pm 0.203$; Cyt c: $1.95 \pm 0.136), 24$ h (Bax: $2.88 \pm 0.101$; Cyt c: $2.23 \pm 0.127$ ) and 48 h (Bax: $2.68 \pm 0.125$; Cyt c: $1.76 \pm 0.138$ ) in rIL-17 treated podocytes (Fig. 6C).

The effects of IL-17 on cellular actin organization were revealed by using Alexa 595-conjugated pholloidin staining in cultured podocytes. Normal podocyte shows a well-organized network of actin cytoskeleton presenting with many thin and long actin filamentous. However, actin filamentous disappeared and cortical cytoskeleton was observed at 12, 24 and $48 \mathrm{~h}$ in rIL-17 treated podocytes (Fig. 6D). 
Fig. 6. Induction of podocyte damage by recombinant IL-17 in cultured mouse podocytes. Podocytes were treated with recombinant IL-17 for different time courses as indicated. (A) The percentage of apoptotic podocytes was measured by using Annexin-V-FITC/PI staining assay. Data are shown as mean \pm SEM. $n=5$ independent experiments. ${ }^{*} p<0.001$ vs. 0 h. (B, C) Total protein was extracted from recombinant IL-17 treated podocytes, and immunoblotting assay was performed for expression of cleaved caspase 3 (B), and Bax and cytochrome c (C), respectively. Data are shown as mean \pm SEM. $\mathrm{n}=3$ independent experiments. ${ }^{*} \mathrm{p}<0.01$ vs. 0 h, ${ }^{\#}$ p 0.001 vs. 0 h. (D) Actin cytoskeleton (red color) was revealed by using Alexa 594 conjugated-phalloidin. Representative images are shown. Bar $=25 \mu \mathrm{m}$.
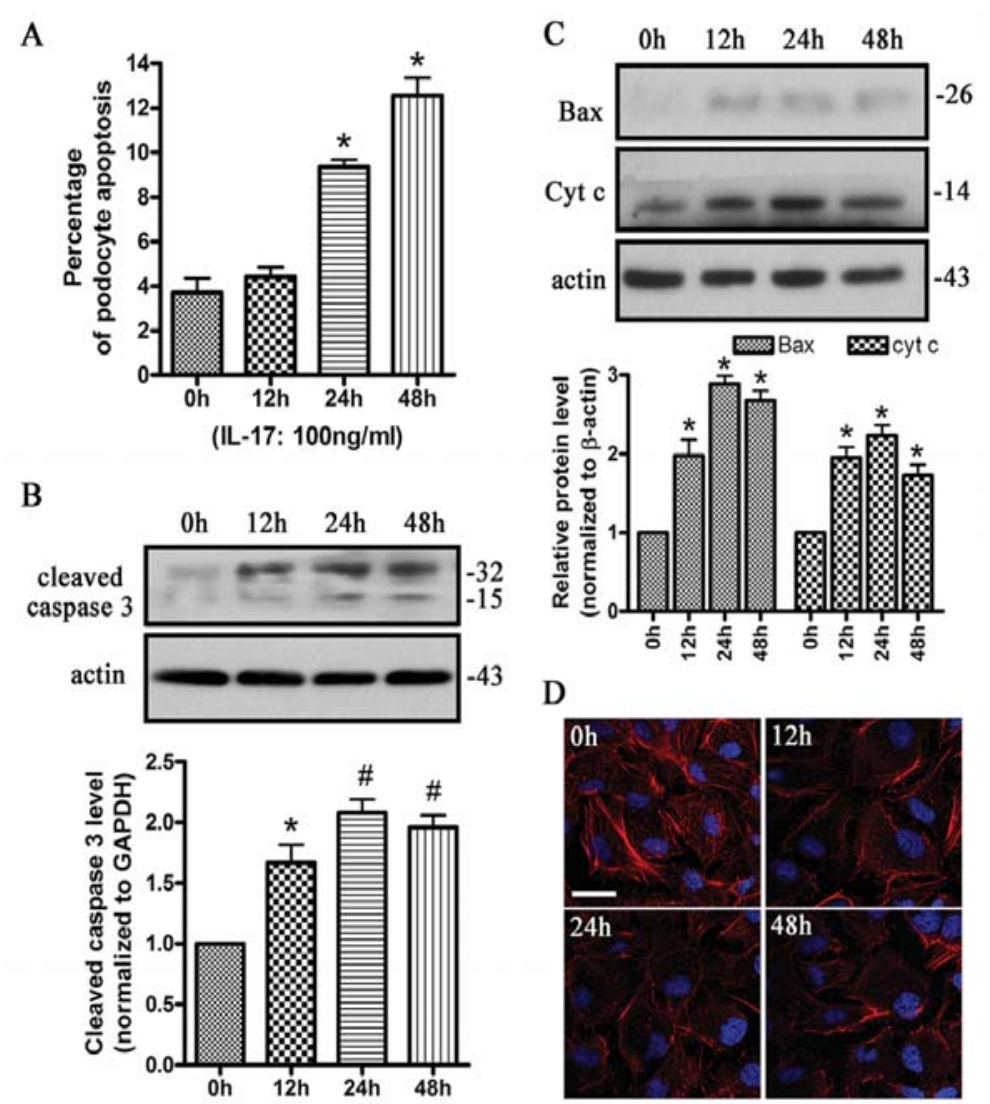

Induction of c-mip and down-regulation of tyrosine phosphorylated nephrin in rIL-17 mediated podocyte damage

The mechanism by which induction of IL-17/IL-17R by ADR led to podocyte damage was explored in rIL-17 mediated podocyte damage model. Quantitative PCR data displayed that the mRNA level of c-mip normalized to control $(0 \mathrm{~h})$ increased significantly $(p<0.01)$ at 24 $\mathrm{h}(1.728 \pm 0.135)$ and $48 \mathrm{~h}(2.082 \pm 0.105)$ following rIL-17 application (Fig. 7A). Moreover, the obvious expression increase of c-mip protein at $24 \mathrm{~h}(2.162 \pm 0.179)$ and $48 \mathrm{~h}(2.928 \pm$ $0.147)$ was confirmed $(p<0.01)$ by Immunoblotting assay in rIL-17 treated podocytes (Fig. 7B).

Tyrosine phosphorylated status of nephrin, a key podocyte protein, is required for maintaining the integrity of slit diaphragm and thus the glomerular filtration filter $[2,3]$. Here, the effects of rIL-17 on nephrin phosphorylation level were evaluated. The level of total nephrin protein that was normalized to control $(0 \mathrm{~h})$ decreased significantly $(p<0.01)$ since $12 \mathrm{~h}(0.615 \pm 0.034)$ continuing to $24 \mathrm{~h}(0.415 \pm 0.028)$ and $48 \mathrm{~h}(0.235 \pm 0.025)$ in rIL17 treated podocytes (Fig. 7C). Notably, tyrosine phosphorylated nephrin level normalized to total nephrin decreased obviously $(p<0.01)$ at $24 \mathrm{~h}(0.533 \pm 0.029)$ and $48 \mathrm{~h}(0.335 \pm$ 0.039) following rIL-17 application (Fig. 7C), suggesting that down-regulation of nephrin phosphorylation may be mediated by induction of IL-17. It is well known that the Src kinase Fyn plays a key role in maintaining tyrosine phosphorylation of nephrin in podocyte [3]. There was no obvious change of total Fyn protein level in cultured podocytes following IL-17 application (Fig. 7D). Nevertheless, the active form (pY418) of Src kinase decreased significantly $(p<0.05)$ while its inactive form (pY529) increased significantly $(p<0.01)$ at $24 \mathrm{~h}$ (pY418: $0.523 \pm$ 0.026; pY529: $1.657 \pm 0.081$ ) and $48 \mathrm{~h}$ (pY418: $0.207 \pm 0.032$; pY529: $2.030 \pm 0.096$ ) in rIL-17 treated podocytes (Fig. 7D). 
A

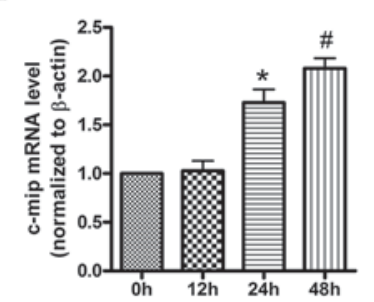

C
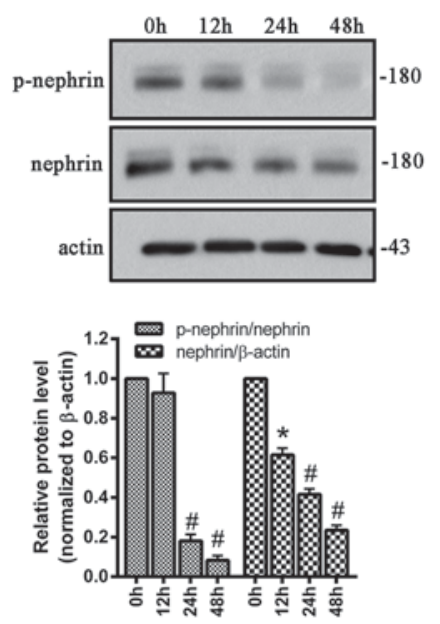

$\mathrm{F}$

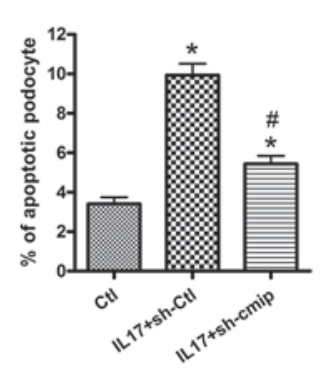

B

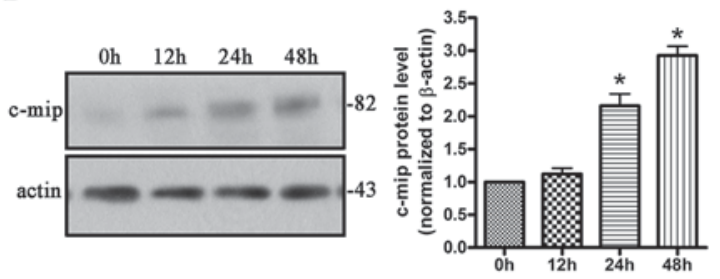

D

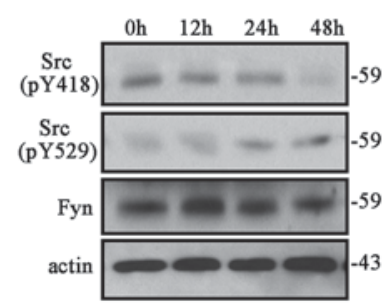

$\mathrm{E}$
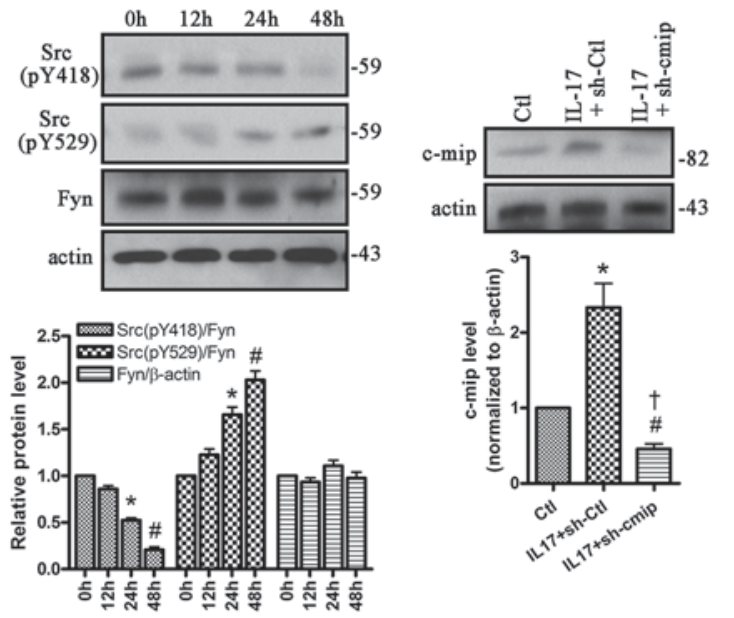

G

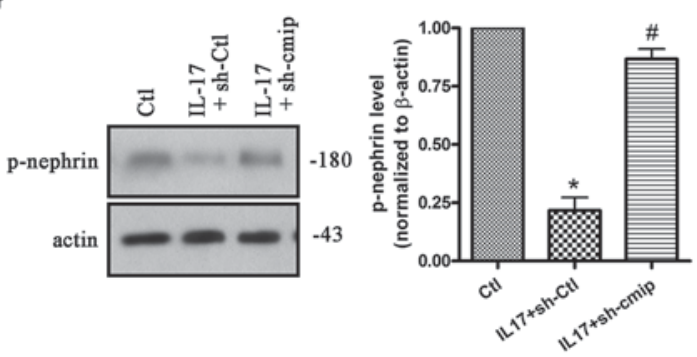

Fig. 7. Induction of c-mip and down-regulation of tyrosine phosphorylated nephrin in IL-17 mediated podocyte damage. Podocytes were treated with $100 \mathrm{ng} / \mathrm{ml}$ of recombinant mouse IL-17 for different time points, and total protein and RNA was extracted. (A - D) The mRNA and protein level of IL-17R was analyzed by using real time PCR (A) and Western blot (B), respectively. Western blot was performed for the expression of tyrosine phosphorylated nephrin and total nephrin (C), respectively. The level of active (pY418) and inactive (pY529) form of Src kinase Fyn was evaluated (D), respectively. Data are shown as mean \pm SEM. $n$ $=3$ independent experiments. ${ }^{*} \mathrm{p}<0.01$ vs. $0 \mathrm{~h},{ }^{*} \mathrm{p}<0.001$ vs. $0 \mathrm{~h}$. (E - G) Podocytes were infected with lantiviral shRNA targeted to mouse c-mip (sh-cmip) or control shRNA (sh-Ctl) for 24 hours, then treated with $100 \mathrm{ng} / \mathrm{ml}$ of recombinant IL-17 for another 24 hours. Knockdown of c-mip was confirmed at protein level by using Western blot (E). Down-regulation of c-mip decreased IL-17 induced-podocyte apoptosis (F). Knockdown of c-mip prevented down-regulation of phosphor-nephrin in IL-17-tretaed podocytes (G). Data are shown as mean \pm SEM. $\mathrm{n}=3$ independent experiments. ${ }^{*} \mathrm{p}<0.01$ vs. Ctl, ${ }^{\#} \mathrm{p}<0.01$ vs. IL- $17+$ sh-Ctl.

It has been reported that c-mip plays an important role in down-regulating nephrin phosphorylation potentially through inhibiting the activation of the Src kinase Fyn [6]. Moreover, induction of c-mip expression has been confirmed in rIL-17 treated podocytes. Thus, the function of c-mip was further investigated by gene silencing assay in rIL-17 induced podocyte damage model. Immunoblotting assay showed that increase of c-mip by rIL-17 application $(2.333 \pm 0.318)$ was prevented robustly $(p<0.01)$ by using shRNA 


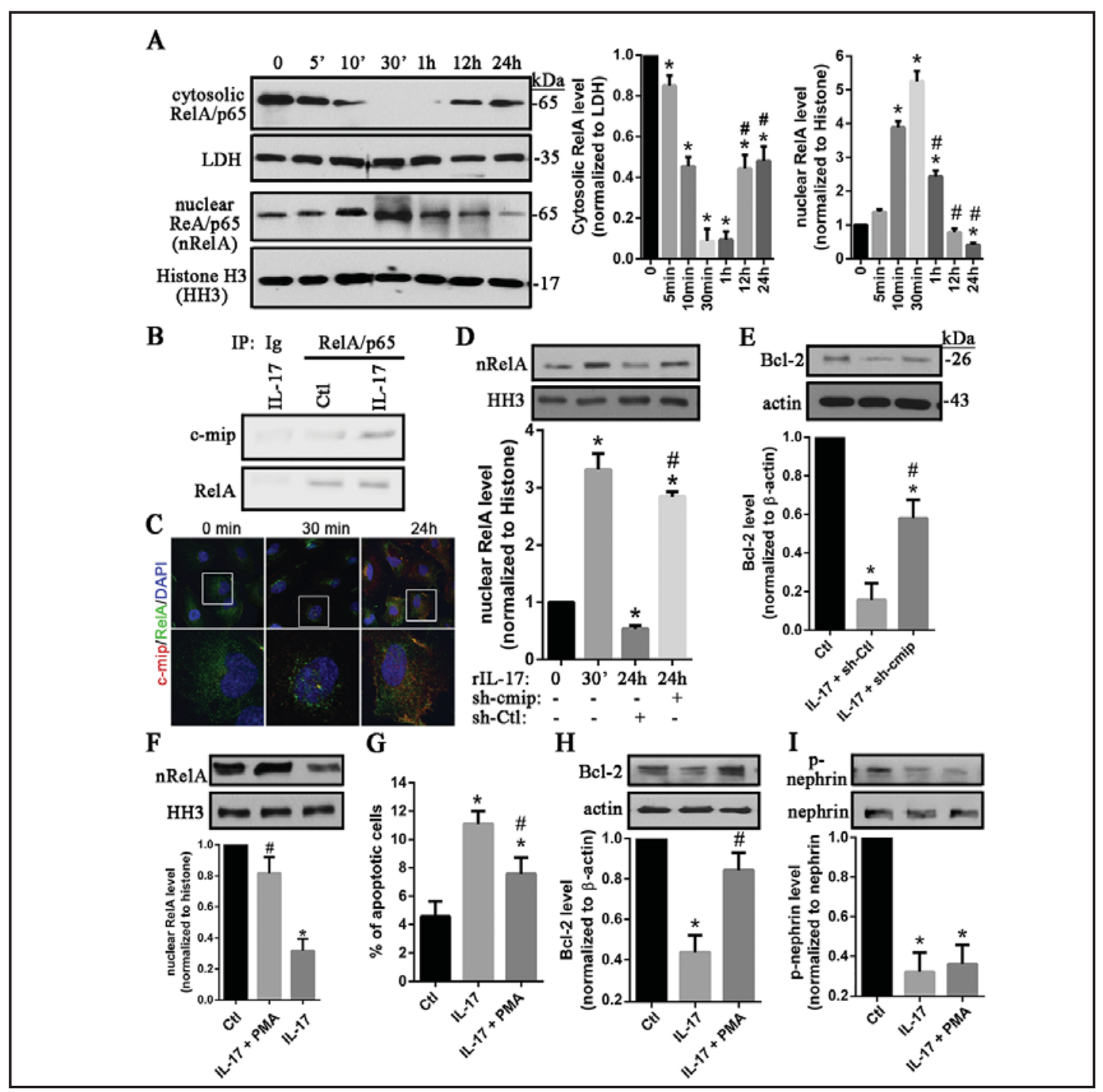

Fig. 8. Perturbation of NF- $\kappa$ B activation by c-mip in IL-17 mediated podocyte damage. Podocytes were treated with $100 \mathrm{ng} / \mathrm{ml}$ of recombinant mouse IL-17 for different time points. Cytosolic, nuclear and total protein was extracted, respectively. (A) The level of cytosolic and nuclear NF- $\kappa B /$ RelA (p65) was analyzed by using Western blot, and quantified by normalization to LDH and Histone H3, respectively. ${ }^{*} \mathrm{p}<0.05$ vs. 0 min, ${ }^{\#} \mathrm{p}<0.05$ vs. 30 min. (B) Podocytes were treated with recombinant IL-17 for $24 \mathrm{~h}$. Interaction of RelA (p65) with c-mip was measured by immunoprecipitation (IP) assay. Normal immunoglobin (Ig) antibody was used as control. (C) Double staining of c-mip and NF- $\kappa \mathrm{B} /$ RelA in recombinant IL-17 treated podocytes. Bar $=12.5$ $\mu \mathrm{m}$. (D) Effects of c-mip silencing by shRNA on the abundance of nuclear NF- $\kappa B$ in podocytes treated with recombinant IL-17 for 24 h. ${ }^{*}$ p 0.05 vs. 0 min, ${ }^{*}$ p $<0.05$ vs. IL-17 + sh-Ctl. (E) Effects of c-mip silencing by shRNA on the abundance of pro-survival protein Bcl-2 was analyzed by using Western blot in podocytes treated with IL-17 for 24 h. ${ }^{*}$ p $<0.05$ vs. 0 min, ${ }^{*}$ p $<0.05$ vs. IL- $17+$ sh-Ctl. (F) Persistent activation of NF- $\kappa B$ was obtained by use of PMA (100 nM) in podocytes treated with IL-17 for $24 \mathrm{~h}$. ${ }^{*}$ p $<0.05$ vs. Ctl, ${ }^{*} \mathrm{p}<0.05$ vs. IL-17. (G) Effects of PMA on cellular apoptosis in podocytes treated with IL-17 for $24 \mathrm{~h}$. ${ }^{*} \mathrm{p}<0.05$ vs. Ctl, " $\mathrm{p}<$ 0.05 vs. IL-17. (H) Effects of PMA on Bcl-2 level in podocytes treated with IL-17 for $24 \mathrm{~h} .{ }^{*} \mathrm{p}<0.05$ vs. Ctl, " $\mathrm{p}$ $<0.05$ vs. IL-17. (I) Effects of PMA on phosphor-nephrin level in podocytes treated with IL-17 for $24 \mathrm{~h}$. $\mathrm{p}<$ 0.05 vs. Ctl. All data are shown as mean \pm SEM. $n=3$ independent experiments.

targeted to mouse c-mip $(0.457 \pm 0.067)$ (Fig. 7E). Podocyte apoptosis induced by rIL-17 $(9.933 \pm 0.581)$ was decreased significantly $(p<0.01)$ in c-mip silencing cells $(5.433 \pm 0.409)$ 


\section{Cellular Physiology Cell Physiol Biochem 2015;36:1274-1290

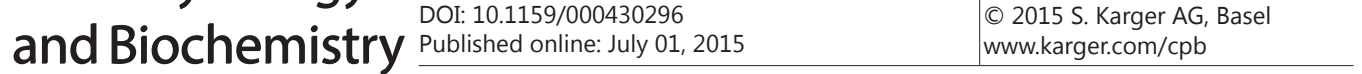

Liu et al.: Role of IL-17-Induced C-Mip in Podocyte Injury

(Fig. 7F). Consistently, down-regulation of phosphor-nephrin in rIL-17 treated podocytes $(0.217 \pm 0.056)$ was effectively $(p<0.01)$ inhibited by c-mip shRNA $(0.866 \pm 0.044)$ (Fig. 7G).

\section{Perturbation of NF- $\kappa B$ activation by c-mip in rIL-17 mediated podocyte damage}

The transcription factors of the NF- $\kappa$ B family are key regulators of immune and inflammatory responses and contribute to cytokine production and cell survival. Following rIL-17 application in cultured podocytes, translocation of NF- $\mathrm{KB} /$ RelA (p65) to nuclei occurred rapidly, peaking at $30 \mathrm{~min}$, and then was disturbed at the late stage $12 \mathrm{~h}$ and $24 \mathrm{~h}$ (Fig. 8A), corresponding to overproduction of c-mip during this period. Interaction of c-mip and RelA (p65) was detected by immunoprecipitation assay at $24 \mathrm{~h}$ after rIL-17 treatment (Fig. 8B), which may be responsible for prevention of NF- $\mathrm{KB}$ translocation. Double staining of c-mip and NF- $\mathrm{KB} /$ RelA showed that RelA was mainly distributed in cytoplasm in normal podocytes, and nuclear NF- $\kappa B$ was obviously observed at $30 \mathrm{~min}$ following rIL17 application. Moreover, colocalization of NF- $\mathrm{KB}$ and the overproduced c-mip was revealed predominantly in cytoplasm at $24 \mathrm{~h}$ in rIL-17 treated podocytes (Fig 8C). Silence of c-mip prompted continuous nuclear translocation of NF- $\mathrm{\kappa B}$ (Fig. 8D), and prevented reduction of anti-apoptotic protein Bcl-2 (Fig. 8E) in rIL-17 treated cells. Persistent activation of NF- $\kappa \mathrm{B}$ was obtained by use of PMA during rIL-17 treatment (Fig. 8F). In rIL-17-treated podocytes, the use of PMA decreased podocyte apoptosis (Fig. 8G) and increased Bcl-2 level (Fig. 8H), but had no effect on phosphor-nephrin level (Fig. 8I).

\section{Discussion}

Podocyte is a predominant and direct target in various proteinuric glomerular diseases including minimal change, the most common nephrotic syndrome (NS) in children. Studies in humans and animal models have shown that the pathogenesis of idiopathic NS is associated with changes in the immune responses, such as the abnormal response of $\mathrm{T}$ lymphocytes and the increased production of local cytokine release $[9,23]$. It is still unclear whether there is a potential relationship between T lymphocyte abnormality and glomerular podocyte injury, and whether there is a putative factor produced by immune cells that can alter podocyte function leading to nephrotic proteinuria.

Recently, increased expression of c-maf inducing protein (c-mip) was found in podocyte as a mechanism for podocyte injury and proteinuria in both human and experimental kidney diseases $[6,7,19,20]$. Initially, c-mip was identified in lymphocytes of NS patients experiencing a relapse [7]. Transgenic mice overexpressing c-mip in podocytes develop heavy proteinuria without any inflammatory lesions or cell infiltration [6]. Here, expression and distribution of c-mip was assessed in AN mice. As previously reported [16], AN was successfully induced in the present study, evidenced by the similar profile of proteinuria, serum albumin and creatinine following ADR injections (Fig 1A-C). In this model, overproduction of c-mip mRNA and protein in kidney cortex was not observed until after day 7 (Fig 1 D, E), while overt proteinuria started at day 5 following ADR injections, suggesting that c-mip is seemingly involved in the progression rather than the development of podocyte injury in this model. The localization of overproduced c-mip in glomeruli was further evaluated by using double staining with a podocyte specific marker synaptopodin. The abundance of synaptopodin decreased slightly in comparison with control, and co-localization of c-mip and synaptopodin was revealed in AN mice glomeruli (Fig 1F), indicating an induction of c-mip in glomerular podocyte by ADR. Up-regulation of c-mip was also reported in angiotensin II-mediated podocyte injury [24]. Interestingly, the increase of c-mip mRNA in PBMC occurred earlier than that in kidney glomerular in AN mice (Fig 1D), suggesting that some serum factors or cytokines may be responsible for the induction of c-mip both in PBMC and glomerular podocytes. Some studies reported that children with NS exhibited a reduction in regulatory $\mathrm{T}$ (Treg) cells that is parallel to an increase in T helper 17 (Th17) cells [13]. In the present study, the percentage of Th17 cells increased remarkably at day 5, persisting to day 21 (Fig 


\section{Cellular Physiology Cell Physiol Biochem 2015;36:1274-1290 \begin{tabular}{l|l}
$\begin{array}{c}\text { DOI: } 10.1159 / 000430296 \\
\text { and Biochemistry }\end{array}$ Published onIIne: July 0I, 2015 & $\begin{array}{l}\text { O 2015 S. Karger AG, } \\
\text { www.karger.com/cpb }\end{array}$
\end{tabular}}

Liu et al.: Role of IL-17-Induced C-Mip in Podocyte Injury

3A), while that of Treg cells decreased remarkably at day 14 and day 21 (Fig 3B), indicating that the balance of Treg and Th17 cells was disturbed in AN mice. The transcription factor Foxp3 and RORyt act in the conversion of naïve CD4+ T cells into Treg and Th17 cells, respectively [13]. Here, the induction of Foxp3 mRNA and the reduction of ROR $\gamma \mathrm{t}$ mRNA in PBMC were verified by quantitative RT-PCR (Fig 3D, E). TGF- $\beta$, IL-6 and IL-23 induce differentiation of CD4+ naïve T cells to Th17 cells, which can produce IL-17 and IL-22 [15]. Nevertheless, Treg cells mainly produce IL-10 and IFN- $\alpha[9,14]$. Therefore, the profiling of serum cytokines was measured in this model. ELISA analysis showed that ADR induced a rapid and robust increase of TGF- $\beta$, IL-6, IL-23 and IL-17, while a remarkable reduction of IL-10 (Fig 2). All of these findings demonstrated an increase of Th17 cells and an induction of serum IL-17 in AN mice.

IL-17 acts as a potent mediator that result in destructive tissue damage by binding to a type I cell surface receptor called IL-17R through a diverse of signal transduction pathway [14]. Notably, the amount of IL-17 in homogenate of kidney cortex from AN mice increased significantly since day 7 and persisted to day 21 (Fig 4A). In human patients with MCNS, mesangial proliferative glomerulonephritis (MsPGN) or Focal segmental glomerulosclerosis (FSGS), immunohistochemistry staining showed that the intensity of IL-17 increased as well in renal biopsy tissue [25]. To explore whether IL-17R was induced in AN mice, mouse glomeruli was isolated by using a sequential sieving procedure, and the purity about $60 \%$ was confirmed under phase contrast microscope (Fig 4B). The amount of glomerular IL17R increased obviously both at mRNA and at protein level in AN mice (Fig 4C, D). Double staining of IL-17R and a podocyte marker podocin displayed that the increased IL-17R was predominantly localized in podocyte (Fig 4E). In cultured mouse podocytes, Immunoblotting assay and immunofluorescence staining showed that ADR application also upregulated the expression of IL-17R (Fig 5), indicating the presence of IL-17R in podocyte. These in vitro and in vivo findings suggest that the overproduced IL-17 by ADR may function on glomerular podocyte by binding to its receptor IL-17R on the surface of poodcyte.

The function of IL-17 was further investigated by applying recombinant mouse IL17 (rIL-17) to cultured podocytes for different time periods. Cellular apoptosis assay revealed that rIL-17 time-dependently led to increase of podocyte apoptosis (Fig 6A). Immunoblotting assay showed that the cleaved caspase 3 as well as the proapoptotic protein Bax and cytochrome c increased remarkably in ADR-treated podocytes (Fig 6B, C). Similarly, it was reported that rIL-17 also promoted podocyte apoptosis, and increased caspase 3 in cultured podocytes [25]. Here, phalloidin staining displayed that rIL-17 also caused disorganization of actin cytoskeleton in cultured podocytes, evidenced by the disappearance of actin filamentous and the induction of actin nucleation (Fig 6D). Moreover, induction of c-mip mRNA and protein was firstly identified in rIL-17 treated podocytes (Fig 7A, B). Immunoblotting assay showed that rIL-17 led to a slight reduction of total nephrin. Nevertheless, it was reported that the same dose of rIL-17 had no effect on the expression of nephrin, but resulted in a decreased expression of another podocyte protein podocalyxin in cultured podocytes [25]. Importantly, phosphor-nephrin level was measured here by quantitative immunoblotting assay, and our data show a dramatic reduction of phosphornephrin by rIL-17 (Fig 7C). It has been demonstrated that overexpressed c-mip binds Fyn and prevents the phosphorylation of nephrin and the recruitment of N-WASP and Nck, thus disturbing downstream signaling events, ultimately resulting in cytoskeleton disorganization and protein leakage [6]. Consistently, the active form $\left(\mathrm{pY}^{418}\right)$ of Src kinase decreased while the inactive form $\left(\mathrm{pY}^{529}\right.$ ) increased in rIL-17-treated podocytes (Fig 7D), implying that the conformation change of Src kinase induced by rIL-17 may be responsible for downregulation of nephrin phosphorylation. In angiotensin II-induced podocyte damage, the activity of Src kinase Fyn was also inhibited by overproduced c-mip [24]. It should be noted that phosphor-nephrin level may be better than total nephrin to be used to assess the effects of injury factor on podocyte pathophysiologies since the active status of nephrin (phosphornephrin level) is required for induction of the downstream signaling. Moreover, knockdown of c-mip was performed by using shRNA specifically targeted to mouse c-mip gene in rIL- 
17-treated podocytes (Fig 7E). Silencing of c-mip decreased cellular apoptosis (Fig 7F), and inhibited down-regulation of nephrin phosphorylation (Fig 7G) in rIL-17 treated podocytes. In LPS nephropathy mice, induction of c-mip was detected, and c-mip knockdown prevented the induction of proteinuria and inactivation of nephrin and Akt [6].

The NF- $\kappa \mathrm{B}$ transcription factors are key intracellular regulators that are induced by immune and inflammatory responses [26]. NF- $\kappa B$ proteins include NF- $\kappa B 2$ (p52/p100), NF$\kappa B 1$ (p50/p105), c-Rel, RelA (p65), and RelB [26]. The hallmark of NF- $\kappa B$ activation is the translocation of dimeric Rel protein to nucleus where, either alone or in combination with other transcription factors, they induce expression of target gene regulating a diverse of biological processes such as cell survival, apoptosis, proliferation, immunity, and inflammation [26]. Following rIL-17 application in cultured podocytes, translocation of NF- $\kappa \mathrm{B} /$ RelA to nuclei occurred very rapidly, which was then disturbed at the late time points $12 \mathrm{~h}$ and $24 \mathrm{~h}$ (Fig. $8 \mathrm{~A}, \mathrm{C}$ ), corresponding to overproduction of c-mip during this period (Fig. 7A, B). It has been reported that c-mip could down-regulate NF- $\mathrm{kB}$ activity by directly binding to RelA, and thus promotes apoptosis [20,27]. By immunoprecipitation and double staining assay, we firstly detected the interaction of c-mip with RelA in rIL-17 damaged podocytes (Fig. 8B, C), which may be responsible for prevention of NF- $\mathrm{KB}$ activation, verified by the finding of c-mip silence that potentiated nuclear translocation of NF- $\kappa B$ (Fig. 8D). NF- $\kappa B$, acting as a double-edged sword, either promotes or prevents cellular apoptosis and inflammation, depending on the cell type and the nature of stimuli. Anyway, the effects resulted from activation of NF- $\kappa \mathrm{B}$ are mediated through a large number of target genes [28]. Pro-survival protein $\mathrm{Bcl}-2$ gene is a major target of NF- $\kappa \mathrm{B}$ in nucleus. Reduction of Bcl-2 was induced by rIL-17 in cultured podocytes, which was prevented by c-mip knockdown (Fig. 8E) or persistent activation of NF- $\kappa B$ by PMA (Fig. 8F, H). Nevertheless, NF- $\kappa B$ relevant target genes are likely regulated by other transcription factors, such as AP1 and C/EBP, and such transcription factors are also likely modulated by other signaling pathway [28]. It should be further studied whether Bcl-2 is a direct target gene of NF- $\kappa \mathrm{B}$ in IL-17 induced podocyte damage. Therefore, the exact role of NF- $\kappa \mathrm{B}$ is not easily obtained until the specific target genes are identified and all involved mechanisms and pathological functions of these target genes are better understood. Just recently, fine-tuning of NF- $\mathrm{BB}$ by GSK3 $\beta$ was clearly clarified in lipopolysaccharide (LPS) or ADR damaged podocyte [29]. Bao et al. provided evidence that overproduced GSK3 $\beta$ by LPS or ADR was sufficient and essential for phosphorylation of RelA/p65 at serine 467, which specifies the expression of selective NF- $\mathrm{kB}$ target molecules including podocytopathic mediators B7-1 and cathepsin L, but not pro-survival protein Bcl-xL [29]. So, blockade of GSK3 $\beta$ by its specific inhibitor TDZD-8 restored cytoskeleton integrity by mitigating the expression of B7-1 and cathepsin L, but barely affected expression of Bcl-xL and potentiated cellular apoptosis [29]. In rIL-17-treated podocytes, the use of PMA decreased podocyte apoptosis (Fig. 8G), but had no effect on phosphor-nephrin level (Fig. 8I). These findings suggest a dual role of overproducing c-mip in IL-17 damaged podocyte. Inhibition of NF- $\mathrm{\kappa B} /$ $\mathrm{Bcl}-2$ pathway by c-mip is responsible for induction of podocyte apoptosis, while inhibition of Src kinase/phosphor-nephrin pathway by c-mip is likely required for actin cytoskeleton disorganization. The findings from the above GSK3 $\beta$ work prompt us to think about whether overproduced c-mip by IL-17 leads to podocyte injury via upregulation of B7-1 and cathepsin $\mathrm{L}$ expression by activating NF- $\kappa \mathrm{B}$, which is useful for us to deeply understand the elaborate function of NF-KB in IL-17 induced podocyte injury. Furthermore, the mechanisms by which IL-17R signaling induces c-mip should be further investigated. In this study, activation of NF- $\kappa B$ occurred rapidly, and then was disturbed in rIL-17 treated podocytes. Induction of c-mip was detected at the late time points. It was reported that IL-17R may activate NF- $\kappa B$ through TRAF6 [30]. We propose that early activation of NF- $\kappa B$ might be mediated by TRAF6, which may be responsible for induction of c-mip. Subsequently, overproduced c-mip could inhibit NF-KB activity by blocking its further nuclear translocation through binding to RelA in cytoplasm. Nevertheless, it has been identified that c-mip promoter has NF- $\kappa B$ binding element, and the binding of NF- $\mathrm{KB} /$ RelA inhibits c-mip transcription in vitro [31]. Therefore, the crosstalk between NF- $\kappa \mathrm{B}$ and c-mip should be further studied. In macrophages, IL-17A 


\section{Cellular Physiology Cell Physiol Biochem 2015;36:1274-1290 \begin{tabular}{ll|l} 
and Bioch 10.1159/000430296 & $\begin{array}{l}\text { ( ) 2015 S. Karger AG, Basel } \\
\text { www.karger.com/cpb }\end{array}$ \\
\hline
\end{tabular}} Liu et al.: Role of IL-17-Induced C-Mip in Podocyte Injury

treatment resulted in the activation of p38MAPK and ERK1/2 and increased DNA-binding activity of NF- $\kappa \mathrm{B}$ and AP-1, and inhibitions of p38, ERK1/2, NF- $\kappa \mathrm{B}$ and AP-1 partially attenuated IL-17A-induced production of TNF- $\alpha$, IL-1 $\beta$, and IL- 6 , indicating that p38MAPKErk1/2-NF- $\kappa$ B pathway may be the downstream signaling of IL-17 [32]. In IL-17 induced podocyte damage model, elucidation of the proximal signaling induced by IL-17 will prompt us to deeply understand the molecular mechanisms by which IL-17R signaling induces c-mip expression. Additionally, our findings that IL-17 is induced in ADR nephropathy mice and that rIL-17 leads to cultured podocyte damage suggest that IL-17 may be involved in podocyte damage and thus proteinuria development. However, the direct evidence whether IL-17 induces podocytopathy and proteinuria in vivo should be further investigated in mice by injection of rIL-17.

In sum, our findings showed that the population of Th17 cells and the serum IL-17 level as well as the abundance of podocyte c-mip and IL-17R was increased in AN mice, and that overproduced c-mip by IL-17 led to cultured podocyte injury through different pathway i) down-regulating phosphor-nephrin level via inhibition of Src kinase activity responsible for actin disorganization, and ii) decreasing Bcl-2 level via inhibition of NF- $\kappa \mathrm{B}$ activity responsible for podocyte apoptosis, respectively.

\section{Disclosure Statement}

None.

\section{Acknowledgements}

This work was supported by the National Natural Science Foundation of China (No. 81170357 to P. Y; No. 30801250 to Q. F).

\section{References}

1 Greenbaum LA, Benndorf R, Smoyer WE: Childhood nephrotic syndrome--current and future therapies. Nat Rev Nephrol 2012;8:445-458.

2 Weening JJ, Ronco P, Remuzzi G: Advances in the pathology of glomerular diseases. Contrib Nephrol 2013;181:12-21.

- 3 Verma R, Wharram B, Kovari I, Kunkel R, Nihalani D, Wary KK, Wiggins RC, Killen P, Holzman LB: Fyn binds to and phosphorylates the kidney slit diaphragm component Nephrin. J Biol Chem 2003;278:20716-20723.

4 New LA, Keyvani Chahi A, Jones N: Direct regulation of nephrin tyrosine phosphorylation by Nck adaptor proteins. J Biol Chem 2013;288:1500-1510.

5 Uchida K, Suzuki K, Iwamoto M, Kawachi H, Ohno M, Horita S, Nitta K: Decreased tyrosine phosphorylation of nephrin in rat and human nephrosis. Kidney Int 2008;73:926-932.

6 Zhang SY, Kamal M, Dahan K, Pawlak A, Ory V, Desvaux D, Audard V, Candelier M, BenMohamed F, Matignon M, Christov C, Decrouy X, Bernard V, Mangiapan G, Lang P, Guellaën G, Ronco P, Sahali D: c-mip impairs podocyte proximal signaling and induces heavy proteinuria. Sci Signal 2010;3:ra39.

7 Grimbert P, Valanciute A, Audard V, Pawlak A, Le gouvelo S, Lang P, Niaudet P, Bensman A, Guellaën G, Sahali D: Truncation of C-mip (Tc-mip), a new proximal signaling protein, induces c-maf Th2 transcription factor and cytoskeleton reorganization. J Exp Med 2003;198:797-807.

8 Ishimoto T, Shimada M, Araya CE, Huskey J, Garin EH, Johnson RJ: Minimal change disease: a CD80 podocytopathy? Semin Nephrol 2011;31:320-325.

9 Pereira Wde F, Brito-Melo GE, Guimarães FT, Carvalho TG, Mateo EC, Simões e Silva AC: The role of the immune system in idiopathic nephrotic syndrome: a review of clinical and experimental studies. Inflamm Res 2014;63:1-12. 


\section{Cellular Physiology Cell Physiol Biochem 2015;36:1274-1290 \begin{tabular}{ll|l} 
and Biochemistry & $\begin{array}{l}\text { DOI: 10.1159/000430296 } \\
\text { Published onlne: July UI, } 2015\end{array}$ & $\begin{array}{l}\text { C 2015 S. Karger AG, Basel } \\
\text { www.karger.com/cpb }\end{array}$ \\
\hline
\end{tabular}}

Liu et al.: Role of IL-17-Induced C-Mip in Podocyte Injury

10 Raphael I, Nalawade S, Eagar TN, Forsthuber TG: T cell subsets and their signature cytokines in autoimmune and inflammatory diseases. Cytokine 2014;S1043-4666(14)00539-0.

11 Cao Q, Wang Y, Zheng D, Sun Y, Wang Y, Lee VW, Zheng G, Tan TK, Ince J, Alexander SI, Harris DC: IL-10/ TGF-beta-modified macrophages induce regulatory t cells and protect against adriamycin nephrosis. J Am Soc Nephrol 2010;21:933-942.

12 Wang YM, Hu M, Wang Y, Polhill T, Zhang GY, Wang Y, Lee VW, Harris DC, Alexander SI: Regulatory T cells in renal disease. Int J Clin Exp Med 2008;1:294-304.

13 Shao XS, Yang XQ Zhao XD, Li Q, Xie YY, Wang XG, Wang M, Zhang W: The prevalence of Th17 cells and FOXP3 regulate T cells (Treg) in children with primary nephrotic syndrome. Pediatr Nephrol 2009;24:1683-1690.

14 Grant CR, Liberal R, Mieli-Vergani G, Vergani D, Longhi MS: Regulatory T-cells in autoimmune diseases: Challenges, controversies and-yet-unanswered questions. Autoimmun Rev 2015;14:105-116.

-15 Singh RP, Hasan S, Sharma S, Nagra S, Yamaguchi DT, Wong DT, Hahn BH, Hossain A: Th17 cells in inflammation and autoimmunity. Autoimmun Rev 2014; 13:1174-1181.

16 Lee VW, Harris DC: Adriamycin nephropathy: a model of focal segmental glomerulosclerosis. Nephrology (Carlton) 2011;16:30-38.

17 Pippin JW, Brinkkoetter PT, Cormack-Aboud FC, Durvasula RV, Hauser PV, Kowalewska J, Krofft RD, Logar CM, Marshall CB, Ohse T, Shankland SJ: Inducible rodent models of acquired podocyte diseases. Am J Physiol Renal Physiol 2009; 96:F213-229.

18 Wang Y, Wang YP, Tay YC, Harris DC: Progressive adriamycin nephropathy in mice: sequence of histologic and immunohistochemical events. Kidney Int 2000;58:1797-1804.

19 Sendeyo K, Audard V, Zhang SY, Fan Q, Bouachi K, Ollero M, Rucker-Martin C, Gouadon E, Desvaux D, Bridoux F, Guellaën G, Ronco P, Lang P, Pawlak A, Sahali D: Upregulation of c-mip is closely related to podocyte dysfunction in membranous nephropathy. Kidney Int 2013;83:414-425.

-20 Ory V, Fan Q, Hamdaoui N, Zhang SY, Desvaux D, Audard V, Candelier M, Noel LH, Lang P, Guellaën G, Pawlak

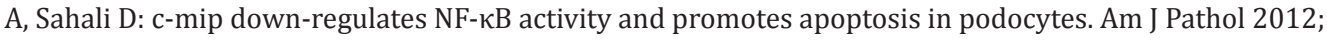
80:2284-2292.

21 Simic I, Tabatabaeifar M, Schaefer F: Animal models of nephrotic syndrome. Pediatr Nephrol 2013;28:2079-2088.

22 Gu C, Wu L, Li X: IL-17 family: cytokines, receptors and signaling. Cytokine 2013;64:477-485.

-23 Couser WG: Basic and translational concepts of immune-mediated glomerular diseases. J Am Soc Nephrol 2012;23:381-399.

-24 Yu L, Lin Q, Feng J, Dong X, Chen W, Liu Q, Ye J: Inhibition of nephrin activation by c-mip through Csk-CbpFyn axis plays a critical role in Angiotensin II-induced podocyte damage. Cell Signal 2013;25:581-588.

25 Wang L, Li Q Wang L, Li C, Yang H, Wang X, Tao H: The role of Th17/IL-17 in the pathogenesis of primary nephrotic syndrome in children. Kidney Blood Press Res 2013;37:332-345.

-26 Rangan G, Wang Y, Harris D: NF-kappaB signalling in chronic kidney disease. Front Biosci (Landmark Ed) 2009;14:3496-3522.

27 Kamal M, Valanciute A, Dahan K, Ory V, Pawlak A, Lang P, Guellaen G, Sahali D: C-mip interacts physically with RelA and inhibits nuclear factor kappa B activity. Mol Immunol 2009;46:991-998.

-28 Karin M, Lin A: NF-kappaB at the crossroads of life and death. Nat Immunol 2002;3:221-227.

-29 Bao H, Ge Y, Peng A, Gong R: Fine-tuning of NFKB by glycogen synthase kinase $3 \beta$ directs the fate of glomerular podocytes upon injury. Kidney Int DOI: 10.1038/ki.2014.428.

-30 Lin D, Li L, Sun Y, Wang W, Wang X, Ye Y, Chen X, Xu Y. IL-17 regulates the expressions of RANKL and OPG in human periodontal ligament cells via TRAF6/TBK1-JNK/NF-KB pathways. Immunology 2014;144:472485.

-31 Izzedine H, Mangier M, Ory V, Zhang SY, Sendeyo K, Bouachi K, Audard V, Péchoux C, Soria JC, Massard C, Bahleda R, Bourry E, Khayat D, Baumelou A, Lang P, Ollero M, Pawlak A, Sahali D: Expression patterns of RelA and c-mip are associated with different glomerular diseases following anti-VEGF therapy. Kidney Int 2014;85:457-470.

32 Chen J, Liao MY, Gao XL, Zhong Q Tang TT, Yu X, Liao YH, Cheng X: IL-17A induces pro-inflammatory cytokines production in macrophages via MAPKinases, NF- $\kappa B$ and AP-1. Cell Physiol Biochem 2013;32:1265-1274. 